\title{
Lyme disease with erythema migrans presenting concurrently with optic nerve perineuritis and abducens nerve palsy
}

\author{
Michael S Lundin (1) ,' Sherri L Sandel, ${ }^{1}$ Corina M Suciu, ${ }^{1}$ Debra A Spicehandler ${ }^{2}$
}

${ }^{1}$ Internal Medicine, Donald and Barbara Zucker School of Medicine at Hofstra/Northwell, Hempstead, New York, USA ${ }^{2}$ Infectious Disease, Donald and Barbara Zucker School of Medicine at Hofstra/Northwell, Hempstead, New York, USA

Correspondence to Dr Michael S Lundin; makala.lundin@gmail.com

Accepted 29 February 2020
Check for updates

(c) BMJ Publishing Group Limited 2020. No commercial re-use. See rights and permissions. Published by BMJ.

To cite: Lundin MS, Sandel SL, Suciu CM, et al. BMJ Case Rep 2020:13:e231889. doi:10.1136/bcr-2019231889

\section{DESCRIPTION}

A 70-year-old man presented to a community hospital in the northern Mid-Atlantic US midsummer with a main problem of severe, stabbing, knife-like pain behind the left eye and a little bit behind the right eye which had started a few days ago but abruptly worsened at 3 o'clock in the morning. He also had a change in the colour perception in his left eye and double vision, which improved when a patch was placed on his left eye. On physical examination, there was moderate left lateral gaze palsy. Funduscopy was not performed. The remainder of the neurologic and ocular examinations was normal. On physical examination, a $15 \mathrm{~cm}$, erythematous, left subaxillary patch resembling a bullseye was incidentally visualised (figure 1).

Medical history was remarkable for stage IV adenocarcinoma of unknown primary diagnosed 6 years prior, assumed to be gastrointestinal per standard practice since below the diaphragm (or possibly pancreaticobiliary), for which the patient was started treatment for with FOLFOX and then FOLFIRI. The most recent chemotherapy was 11 days ago with FOLFIRI and a single dose of dexamethasone. He also had a history of deep venous thrombosis of the left leg a few years ago and superior mesenteric vein thrombosis 6 months ago (currently on anticoagulation), diabetes mellitus, and cirrhosis. There was no history of optic neuritis, multiple sclerosis, nerve problems or autoimmune

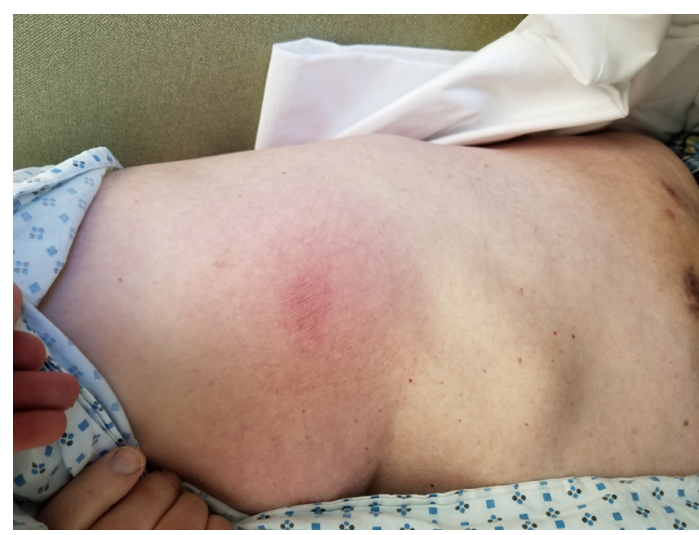

Figure 1 The patient exhibits a $15 \mathrm{~cm}$ erythematous, blanchable, non-pruritic, non-painful, subaxillary bulls-eye patch which he had not noticed and was only visualised on presentation. This photograph was taken 2 days later, by which time the rash's size and redness had diminished considerably.

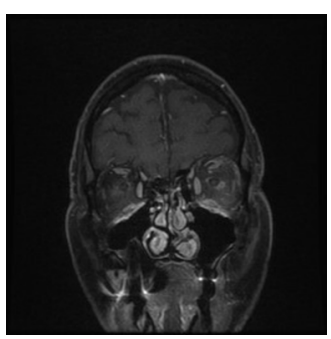

Figure 2 MRI shows prominent asymmetric enhancement of the left optic sheath most pronounced along the orbital segment of the left optic nerve, just proximal to the intraorbital segment. A coronal view.

disease. Despite the patient's comorbidities, he was active and of excellent performance status.

Lyme disease serum serology using LIAISON quantitative chemiluminescence was positive at 3.45 index for IgG and IgM to Borrelia burgdorferi (reference is $<1$ ). Second-stage testing with western blot was omitted because further specificity was not needed, given the patient's stereotypical erythema migrans (EM) and the rather high incidence of false negatives in the western blot (occurring as often as $50 \%$ of the time in some circumstances). ${ }^{1-3}$ EM in high-risk patients, such as ours, is specific for Lyme disease and antimicrobial therapy is indicated independent of any tests (which are often not even performed outpatient, as they are frequently falsely negative in the acute window period). ${ }^{134}$ The patient, who lived in a wooded area with deer, did not recall any tick exposure; however, only one out of every four patients with Lyme disease do. ${ }^{5}$ In any case, cerebrospinal fluid (CSF) was clear and colourless with a total cell count of 20: 1 neutrophil, 15 lymphocytes and 4 monocytes. There were zero erythrocytes. CSF total protein and glucose were both $67 \mathrm{mg} / \mathrm{dL}$. CSF Lyme disease antibody, using the same chemiluminescence study as for the serum, was borderline at 0.127 (reference $<0.117$ ). MRI of the brain and orbits with and without contrast (figures 2 and 3) showed enhancement of the left optic sheath most pronounced along the orbital segment of the left optic nerve, just proximal to the intraorbital segment. Since the patient had the typical EM rash and it responded to treatment, more extensive workup for optic neuritis was not pursued. Abducens nerve palsy also frequently occurs in diabetes mellitus, but this was considered less likely with the EM rash. Intravenous ceftriaxone was initiated for Lyme disease as well as empiric doxycycline for any possible concurrent subclinical 


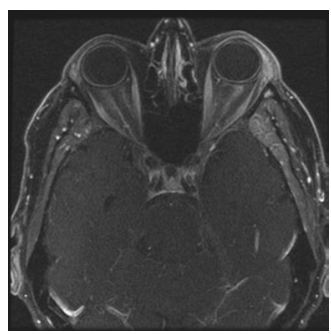

Figure 3 MRI shows prominent asymmetric enhancement of the left optic sheath most pronounced along the orbital segment of the left optic nerve, just proximal to the intraorbital segment. An axial view.

rickettsial zoonosis. Corticosteroids were not used because the optic perineuritis was thought to be secondary to the Lyme disease. The patient's EM abated and his neuro-ophthalmologic symptoms improved. He was discharged 3 days later to complete a course of 4 weeks of intravenous ceftriaxone and his symptoms did not recur.

This case is important because while abducens nerve palsy or multifocal disease is not atypical of neuroborreliosis, ${ }^{6}$ optic neuritis in association with Lyme disease is rare. ${ }^{7}$ In 2005 , retrospective data suggested that optic neuritis occurs rarely secondary to Lyme disease. ${ }^{8}$ Authors of a 2007 report of active Lyme disease associated with optic neuritis cautiously prefaced their case by informing the reader that none of 14 previous cases in the literature that they examined fulfilled the Halperin or Sibony criteria for active Lyme disease. ${ }^{9}$ However, since that time, more cases have emerged describing optic neuritis due to underlying Lyme disease. ${ }^{10} 11$ This case is interesting because the perineuritis symptoms resemble optic neuritis.

As a side note, this case is also interesting because the EM presented at the same time as the neuro-ophthalmologic symptoms. Human spirochetal illnesses (such as those caused by Treponema, Leptospira or Borrelia) are classically characterised as having three distinct clinical stages. ${ }^{12}{ }^{13} \mathrm{EM}$ is a sign of early, localised disease, most often appearing within a month after infection, whereas arthritis, carditis and neurological disease are typical of later stages. The positive serology in our patient suggests that the patient had been infected by B. burgdorferi

\section{Learning points}

While it may have been a concurrence, this case may demonstrate a rare manifestation of Lyme neuroborreliosis: optic perineuritis (together with abducens palsy and erythema migrans (EM)).

- Eighty per cent of the time, Lyme disease initially presents with a bulls-eye rash named EM, which is a quite specific feature. However, Lyme disease sometimes does not present with $\mathrm{EM}$ and can linger to present later with various manifestations, including neurologic, rheumatologic and cardiac disease. already for some time before the EM appeared. Perhaps some of the presentation can be explained by the patient's immunosuppression. Another interesting feature of this case is that the patient had some mild symptoms in his second eye, and bilaterality is a feature sometimes observed in Lyme disease (such as in Lyme cranial neuropathy) ${ }^{1314}$ as opposed to in other neurologic disorders.

We were fortunate that our patient had EM, which made our diagnosis and treatment relatively straightforward. However, only $80 \%$ of patients with Lyme disease develop $\mathrm{EM}^{215}$ and it usually occurs in the early, localised stage. As such, some readers may interpret this case as supporting keeping Lyme disease on the differential.

Acknowledgements We wish to acknowledge Charles Elkin MD in the department of radiology at our institution.

Contributors ML wrote the manuscript. SS edited and revised the manuscript twice, making substantial changes. CS and DS saw the patient, reviewed the manuscript and gave substantial input.

Funding The authors have not declared a specific grant for this research from any funding agency in the public, commercial or not-for-profit sectors.

Competing interests None declared.

Patient consent for publication Obtained.

Provenance and peer review Not commissioned; externally peer reviewed.

ORCID iD

Michael S Lundin http://orcid.org/0000-0002-8078-8795

\section{REFERENCES}

1 Aguero-Rosenfeld ME, Wang G, Schwartz I, et al. Diagnosis of Lyme borreliosis. Clin Microbiol Rev 2005;18:484-509.

2 Steere AC, Sikand VK. The presenting manifestations of Lyme disease and the outcomes of treatment. N Engl J Med 2003;348:2472-4.

3 Wormser GP, Nowakowski J, Nadelman RB, et al. Impact of clinical variables on Borrelia burgdorferi-specific antibody seropositivity in acute-phase sera from patients in North America with culture-confirmed early Lyme disease. Clin Vaccine Immunol 2008;15:1519-22.

4 Steere AC, McHugh G, Damle N, et al. Prospective study of serologic tests for Lyme disease. Clin Infect Dis 2008;47:188-95.

5 Nadelman RB, Nowakowski J, Forseter $\mathrm{G}$, et al. The clinical spectrum of early Lyme borreliosis in patients with culture-confirmed erythema migrans. Am J Med 1996;100:502-8.

6 Chaturvedi A, Baker K, Jeanmonod D, et al. Lyme disease presenting with multiple cranial nerve deficits: report of a case. Case Rep Emerg Med 2016;2016:1-3.

7 Träisk F, Lindquist L. Optic nerve involvement in Lyme disease. Curr Opin Ophthalmol 2012:23:485-90

8 Sibony P, Halperin J, Coyle PK, et al. Reactive Lyme serology in optic neuritis. J Neuroophthalmol 2005;25:71-82.

9 Krim E, Guehl D, Burbaud P, et al. Retrobulbar optic neuritis: a complication of Lyme disease? J Neurol Neurosurg Psychiatry 2007;78:1409-10.

10 Blanc F, Ballonzoli L, Marcel C, et al. Lyme optic neuritis. J Neurol Sci 2010;295:117-9.

11 Jha P, Rodrigues Pereira SG, Thakur A, et al. A case of optic neuritis secondary to Lyme disease. WMJ 2018;117:83-7.

12 Pachner AR. Borrelia burgdorferi in the nervous system: the new "great imitator". Ann NYAcad Sci 1988;539:56-64.

13 Agarwal R, Sze G. Neuro-lyme disease: MR imaging findings. Radiology 2009;253:167-73

14 Hildenbrand $\mathrm{P}$, Craven DE, Jones $\mathrm{R}$, et al. Lyme neuroborreliosis: manifestations of a rapidly emerging zoonosis. AJNR Am J Neuroradiol 2009;30:1079-87.

15 Shapiro ED, Disease L. Clinical practice. Lyme disease.. N Engl J Med 2014:370:1724-31. 
Copyright 2020 BMJ Publishing Group. All rights reserved. For permission to reuse any of this content visit https://www.bmj.com/company/products-services/rights-and-licensing/permissions/

BMJ Case Report Fellows may re-use this article for personal use and teaching without any further permission.

Become a Fellow of BMJ Case Reports today and you can:

- Submit as many cases as you like

- Enjoy fast sympathetic peer review and rapid publication of accepted articles

Access all the published articles

Re-use any of the published material for personal use and teaching without further permission

Customer Service

If you have any further queries about your subscription, please contact our customer services team on +44 (0) 2071111105 or via email at support@bmj.com.

Visit casereports.bmj.com for more articles like this and to become a Fellow 